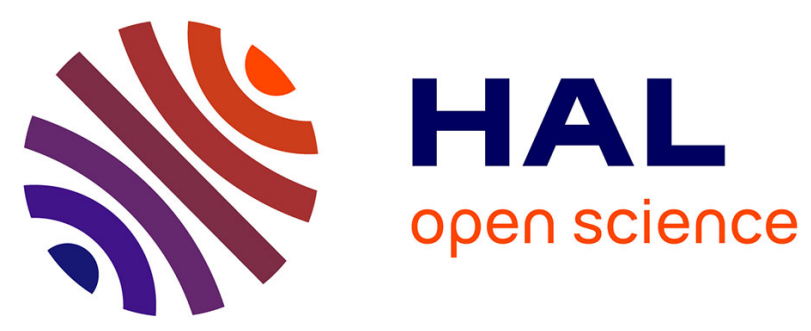

\title{
A systematic link between microstructure and acoustic properties of foams: A detailed study on the effect of membranes
}

van Hai Trinh, Minh Tan Hoang, Camille Perrot, Vincent Langlois, Yacine Khidas, Olivier Pitois

\section{To cite this version:}

van Hai Trinh, Minh Tan Hoang, Camille Perrot, Vincent Langlois, Yacine Khidas, et al.. A systematic link between microstructure and acoustic properties of foams: A detailed study on the effect of membranes. The 6th Biot Conference on Poromechanics (BiotConf 2017), Jul 2017, Paris, France. hal-01664267

\section{HAL Id: hal-01664267 \\ https://hal.science/hal-01664267}

Submitted on 14 Dec 2017

HAL is a multi-disciplinary open access archive for the deposit and dissemination of scientific research documents, whether they are published or not. The documents may come from teaching and research institutions in France or abroad, or from public or private research centers.
L'archive ouverte pluridisciplinaire HAL, est destinée au dépôt et à la diffusion de documents scientifiques de niveau recherche, publiés ou non, émanant des établissements d'enseignement et de recherche français ou étrangers, des laboratoires publics ou privés. 


\title{
A systematic link between microstructure and acoustic properties of foams: A detailed study on the effect of membranes
}

\author{
Van Hai Trinh ${ }^{1,2, a}$, Minh Tan Hoang ${ }^{1, b}$, Camille Perrot ${ }^{1, c}$, \\ Vincent Langlois $^{3}$, Yacine Khidas ${ }^{4, d}$, Olivier Pitois ${ }^{4, e}$ \\ ${ }^{1}$ Université Paris-Est, Laboratoire Modélisation et Simulation Multi Echelle, MSME UMR 8208 \\ CNRS, 5bd Descartes, 77454 Marne-la-Vallée, France; e-mail: van-hai.trinh@u-pem.fr; \\ bminh-tan.hoang@faurecia.com; ${ }^{c}$ camille.perrot@u-pem.fr \\ ${ }^{2}$ Le Quy Don Technical University, 236 Hoang Quoc Viet St, Ha Noi, Vietnam \\ ${ }^{3}$ Université Paris-Est, Laboratoire Géomatériaux et Environnement, LGE EA 4508, 77454, \\ Marne-la-Vallée, France ; e-mail: vincent.langlois@u-pem.fr \\ ${ }^{4}$ Université Paris-Est, Laboratoire Navier, NAVIER UMR 8205 CNRS, Champs-sur-Marne, \\ France; e-mail: ${ }^{\mathrm{d}}$ yacine.khidas@u-pem.fr; ${ }^{\mathrm{e}}$ olivier.pitois@ifsttar.fr
}

\begin{abstract}
In this study, we show how milli-fluidic tools can be used to elaborate polymer foams with tunable microstructural parameters, such as the size and the connectivity of the pores. We produce several samples having the same density and the same monodisperse pore size but different values of the closure rate of the windows separating the foam pores, which is estimated by measuring the proportion of closed cells and the size distribution of apertures for open-wall cells. This distribution is based on a distinction between the windows counting four or less edges from the windows counting more than four edges. Then a representative unit cell is reconstructed to mimic the main feature of microstructure information and serves as the basis to the computation of the sound absorbing parameter, using numerical homogenization techniques. Very good correspondences between numerical results and experimental measurements were observed. Our analysis reveals a significant dependence of membrane level on the sound absorption behavior of these foams.
\end{abstract}

\section{INTRODUCTION}

Solid foams are desirable materials for use in many applications where acoustical and/or mechanical energy absorption properties are required. Different methods have been proposed to predict the link between microstructural parameters and those properties [1-4].

To this regard, it has been shown that foam membranes, i.e. the solid films closing the windows separating the foam pores, can be of primary importance in acoustical capacity whereas they may occupy a very small volume fraction within the material. Accounting for the membranes effect led to the introduction of dedicated parameters, by measuring simply the fraction of open windows $[4,5]$ or distinguishing both fully open and partially open windows [6-11]. From such a 
refined microstructural description, the homogenization method was found to predict successfully the acoustic properties of several polyurethane foam samples [9-11]. However, the complete validation of such method would require considering a set of foam samples allowing for the membrane parameter to be varied within a significant range of values. In this study, we elaborate polymer foam samples showing several membrane contents. The classical numerical homogenization method based on the local geometry models of these real membrane foams is employed to calculate the macroscopic transport properties. The sound absorption performance is derived from macroscopic properties using the semi-phenomenological Johnson-ChampouxAllard-Lafarge (JCAL) model [12-14]. Finally, the predicted sound absorption and transport parameters are compared with measurements using a three-microphone impedance tube.

\section{EXPERIMENTS}

Elaboration of controlled polymer foams: We elaborate solid polymer foam samples having a gas volume fraction $\phi$ and a monodisperse pore size $D_{b}$, but a tunable membrane content. The experimental procedure can be described as follows: (1) monodisperse precursor aqueous foam is generated. Foaming liquid, i.e. TTAB at $3 \mathrm{~g} / \mathrm{L}$ in water, and nitrogen are pushed through a Tjunction allowing controlling the bubble size by adjusting the flow rate of each fluid. Produced bubbles are stored in a glass column and a constant liquid fraction over the foam column is set at 0.99 by imbibition from the top with foaming solution. (2) An aqueous gelatin solution is prepared at a mass concentration $C_{g e l}$ within the range $12-18 \%$. The temperature of this solution is maintained at $\mathrm{T} \approx 60^{\circ} \mathrm{C}$ in order to remain above the sol/gel transition $\left(30^{\circ} \mathrm{C}\right)$. (3) The precursor foam and the hot gelatin solution are mixed in a continuous process thanks to a mixing device based on flow-focusing method [15]. By tuning the flow rates of both the foam and the solution during the mixing step, the gas volume fraction can be set, $\phi_{0}=0.8$. Note also that the bubble size is conserved during the mixing step. The resulting foamy gelatin is continuously poured into a cylindrical cell (diameter: $40 \mathrm{~mm}$ and height: $40 \mathrm{~mm}$ ) which is rotating around its axis of symmetry at approximately $50 \mathrm{rpm}$. This process allows for gravity effects to be compensated until the temperature decreases below the setting temperature. (4) The cell is let one hour at $5^{\circ} \mathrm{C}$, then one week in a climatic chamber $\left(\mathrm{T}=20^{\circ} \mathrm{C}\right.$ and $\left.\mathrm{RH}=30 \%\right)$. During that stay, water evaporates from the samples and the gas fraction increases significantly. (5) After unmolding, a slice (thickness: $20 \mathrm{~mm}$ and diameter: $40 \mathrm{~mm}$ ) is cut.
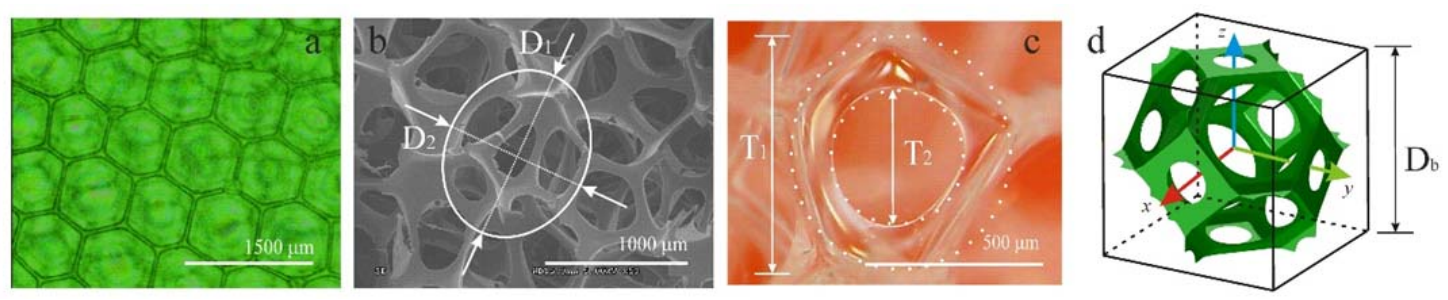

Figure 1: Characterizations of dried-gelatin foams materials: illustrations of the top of a cut sample (a), the degree of anisotropy (b), the closure rate of a window (c), and a periodic unit cell (d). 
Characterization of the foam samples. As the density of the dried gelatin was measured to be 1.36 volume and weight measurements of the prepared samples give the pore volume fraction. For the gelatin concentrations used in this study, the pore volume fraction was found to vary between 0.977 and 0.983 , so that in the following we will consider that this parameter is approximately constant and equal to $\phi=0.980 \pm 0.003$. Observation of the cylindrical surface of the sample (see Fig. 1a) allows for the pore (bubble) size to be measured: $D_{b}=810 \mu \mathrm{m}$ (the absolute error on $D_{b}$ is $\pm 30 \mu \mathrm{m}$ ) for all the samples. In addition, the shape anisotropy degree was estimated through a ratio as $a_{1}=D_{1} / D_{2}$ (see Fig. $1 \mathrm{~b}$, note that this degree is also considered in both axial and radial directions), providing values smaller than 1.15 for all samples, which justify to neglect this effect in the following. The membrane content is evaluated by measuring the closure rate of windows separating the pores. We proceed as follows: over several hundred windows observed on both top and bottom sample surfaces, the proportion of fully closed windows $x_{f c}$ is measured. For the partially closed windows $x_{p}$, with a proportion equal to $\left(1-x_{f c}\right)$, their average closure degree is also measured: $r_{c}=1-T_{2} / T_{1}$, where $T_{1}$ is the window size (the diameter/mean diameter of a circle/an ellipse enclosing the vertex of the corresponding polygonal face) and $T_{2}$ is the window opening (the diameter/mean diameter of a circle/an ellipse inscribed into the cell aperture) - see Fig. 1c. According to these notations, the membrane closed fraction writes: $f_{c}=x_{f c}+\left(1-x_{f c}\right) r_{c}$. Note that in order to get all the structural information required for the modeling, we refine this treatment by distinguishing the windows counting 4 or less edges (referred to as ' $s q$ '), from the windows counting more than 4 edges (referred to as 'hex'). The structural characterization was completed by a measurement of the membrane thickness through SEM microscopy. From ten SEM images we obtain an average thickness equal to $1.5 \pm 0.25 \mu \mathrm{m}$, which is close to thicknesses measured for similar polymer foams $[6,9,11]$.

The static air flow resistivity $\sigma$ of $L_{s}$-thick sample is obtained from the measured differential pressures $\Delta p$ and the controlled steady laminar flow rate $Q$ [16], according to the standard ISO $9053(\operatorname{method} \mathrm{A}): \sigma=\Delta p L_{s} / Q$. The relative error is between $5 \%$ and $10 \%$.

Acoustic properties are determined with a 3-microphone impedance tube [17, 18] (length: 1 $\mathrm{m}$, diameter: $40 \mathrm{~mm}$ ). Separating distances are: Micro.1-Micro.2: $35 \mathrm{~mm}$, Micro.2-Sample: $80 \mathrm{~mm}$, Sample-Micro.3: $0 \mathrm{~mm}$. Note that the diameter of the samples was slightly larger than $40 \mathrm{~mm}$ so that air leakage issue and sample vibration were successfully avoided. The test frequency ranges from $4 \mathrm{~Hz}$ to $4500 \mathrm{~Hz}$ with a step size of $4 \mathrm{~Hz}$.

\section{MULTI-SCALE MODELING OF ACOUSTIC MATERIALS}

Macro-scale model. From the macroscopic perspective the equivalent-fluid approach is applied where a rigid porous medium is substituted by an effective fluid characterized by the effective density [12] and effective bulk modulus [13, 14] given as follows:

$$
\rho(\omega)=\rho_{0}\left[\alpha_{\infty}+\frac{\phi \sigma}{j \omega \rho_{0}} \sqrt{1+j \omega \frac{\rho_{0}}{\eta}\left(\frac{2 \eta \alpha_{\infty}}{\sigma \phi \Lambda}\right)^{2}}\right],
$$




$$
K(\omega)=\frac{\gamma P_{0} / \phi}{\gamma-(\gamma-1)\left[1-j \frac{\phi \kappa}{k_{0}^{\prime} C_{p} \rho_{0} \omega} \sqrt{1+j \frac{4 k_{0}^{\prime 2} C_{p} \rho_{0} \omega}{\kappa \Lambda^{\prime 2} \phi^{2}}}\right]^{-1}}
$$

where $\rho_{0}$ is the density of air at rest, and $\kappa=\gamma P_{0}$ is the air adiabatic bulk modulus, $P_{0}$ the atmospheric pressure, $\gamma=C_{p} / C_{v}$ is the ratio of heat capacity at constant pressure $\left(C_{p}\right)$ to the heat capacity at constant volume $\left(C_{v}\right)$.

The homogeneous layer is described by the wave number $k(\omega)$ and the characteristic impedance $Z_{c}(\omega)$ as follows,

$$
k(\omega)=\omega \sqrt{\rho(\omega) / K(\omega)}, \quad Z_{c}(\omega)=\sqrt{\rho(\omega) K(\omega)}
$$

The normal incidence sound absorption coefficient of a porous layer is derived from the complex reflection coefficient $R$ :

$$
\alpha=1-|R|^{2}, \quad R=\left(Z_{s}-\rho_{0} c_{0}\right) /\left(Z_{s}+\rho_{0} c_{0}\right)
$$

with $c_{0}$ is the sound speed in air and $Z_{s}$ is the normal incidence surface impedance. For a layer of thickness $L_{s}$, this impedance is given by $Z_{s}(\omega)=-j Z_{c} / \phi \operatorname{cotg} k L_{s}$.

Micro-scale model. Eq. (1) and (2) involve 6 parameters ( $\phi, \Lambda^{\prime}, \sigma, \alpha_{\infty}, \Lambda$ and $\left.k_{0}^{\prime}\right)$ : the porosity $\phi$ and the thermal characteristic length $\Lambda^{\prime}$ are defined from local geometry, and others are computed from the numerical solutions of (i) the Stokes equations [12] (the static air flow resistivity $\sigma$ ); (ii) the potential flow equations [12] (the high frequency tortuosity $\alpha_{\infty}$ and the viscous characteristic length $\Lambda$ ); and (iii) the equations of the diffusion controlled reactions [19] (the static thermal permeability $k_{0}^{\prime}$ ). A detailed view is provided in Ref. [20].

Local geometry model. A periodic unit cell (PUC) is used to represent the structure of our foam samples [2]. The cell is based on the Kelvin paving and is 14-sided polyhedron: 8 hexagons and 6 squares. As we are mostly interested in the effect of the closure rate of windows, the cell skeleton is made of idealized ligament having a length $L=D_{b} / 2 \sqrt{2}$ and an equilateral triangular cross section of edge side $r=0.62 D_{b}(1-\phi)^{0.45}[21]$. The global closure rate of the cell can be tuned by varying the number of partially closed windows, i.e. $N_{p}^{s q} \approx 6 \times x_{p}^{s q} /\left(x_{p}^{s q}+x_{f c}^{s q}\right)$ and $N_{p}^{\text {hex }} \approx 8 \times\left(x_{p}^{\text {hex }}+x_{f c}^{\text {hex }}\right)$, as well as the closure level of those windows, i.e. $r_{c}^{s q}$ and $r_{c}^{\text {hex }}$ respectively (details are given in the characterization section). The number of fully closed windows is equal to $N_{f c}^{s q}=6-N_{p}^{s q}$ and $N_{f c}^{\text {hex }}=8-N_{p}^{\text {hex }}$.

\section{RESULTS AND DISCUSSION}

Results for both airflow resistivity measurements and structural characterization reveal that the gelatin concentration $C_{g e l}$ in the foaming solution controls the closure rate of cell windows (see Tab. I): $f_{c}$ varies from $\sim 30 \%$ to $\sim 80 \%$ when $C_{g e l}$ varies from $12 \%$ to $18 \%$ and measured results of static resistivity show a significant increase upon the high level of $f_{c}$. Note that the resistivity 
Table I. Static resistivity and microstructural parameters measured on foam samples.

\begin{tabular}{cccccccccccc}
\hline \multirow{2}{*}{ Sample } & $\begin{array}{c}C_{g e l} \\
(\%)\end{array}$ & $\begin{array}{c}\sigma \\
\left(\mathrm{kNsm}^{-4}\right)\end{array}$ & $\begin{array}{c}x_{p}^{s q} \\
(\%)\end{array}$ & $\begin{array}{c}x_{f c}^{s q} \\
(\%)\end{array}$ & $\begin{array}{c}x_{p}^{\text {hex }} \\
(\%)\end{array}$ & $\begin{array}{c}x_{f c}^{\text {hex }} \\
(\%)\end{array}$ & $N_{p}^{s q}$ & $N_{p}^{\text {hex }}$ & $r_{c}^{s q}$ & $r_{c}^{\text {hex }}$ & $\begin{array}{c}f_{c} \\
(-)\end{array}$ \\
\hline $\mathrm{A}_{1}$ & 12 & 1.6 & 20.6 & 5.6 & 70.5 & 3.3 & 5 & 8 & 0.247 & 0.225 & 29 \\
$\mathrm{~A}_{2}$ & 13 & 3.0 & 18.4 & 8.1 & 64.9 & 8.6 & 4 & 7 & 0.302 & 0.296 & 45 \\
$\mathrm{~A}_{3}$ & 16 & 10.0 & 10.4 & 19.8 & 49.3 & 20.6 & 2 & 6 & 0.411 & 0.383 & 65 \\
$\mathrm{~A}_{4}$ & 18 & 40.0 & 6.6 & 22.1 & 42.6 & 28.7 & 1 & 5 & 0.615 & 0.531 & 81 \\
\hline
\end{tabular}

corresponding to sample $\mathrm{A}_{4}$ is a characterized value obtained from the imaginary part of the low frequency behavior of the effective density [22], because it is out of the device's accessible measurement range. For all the samples, the ratio $\left(x_{p}^{s q}+x_{f c}^{s q}\right) /\left(x_{p}^{\text {hex }}+x_{f c}^{\text {hex }}\right)$ is close to $1 / 3$, which is consistent with previous works [23, 24].

Fig. 1d illustrates the geometrical characteristics of a tetrakaidecahedron with dimensions $D_{b}$. At each squared or hexagonal face of the unit-cell, a very thin plate with round holes bridging together the ligaments is modeled to represent the foam membranes (or solid films). A set of 4 unit cells is presented with the morphology originating $\left(N_{p}^{s q}, N_{f c}^{s q}, N_{p}^{\text {hex }}, N_{f c}^{h e x}, r_{c}^{s q}\right.$ and $\left.r_{c}^{\text {hex }}\right)$ from the collected measurements (see Tab. I) to characterize samples $A_{1-4}$. The transport and sound absorbing properties of each foam sample were derived from these elementary cells. Note that in the computations the external excitation force for which the solution is computed corresponds to the $x$-direction.
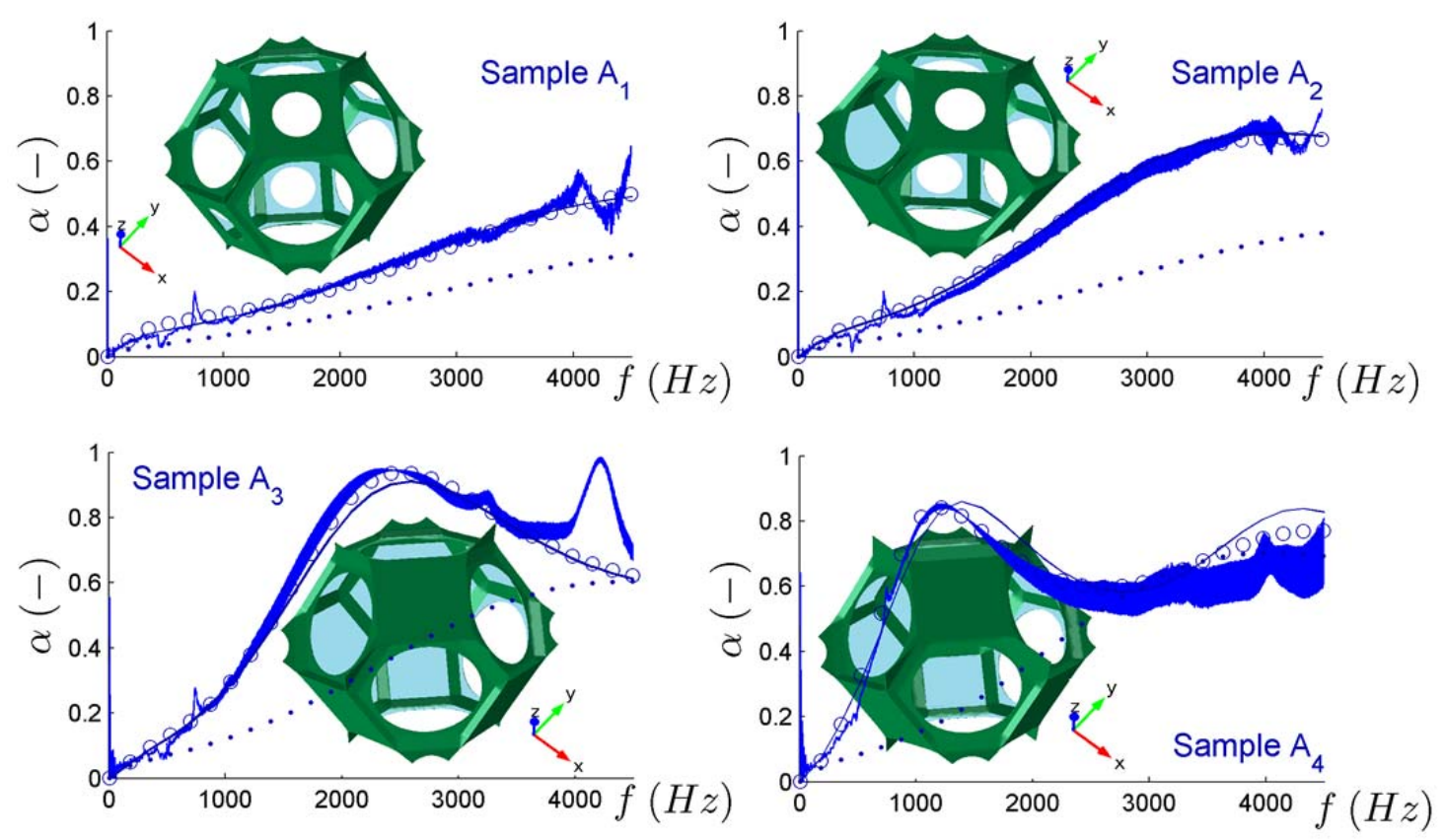

Figure 2: Sound absorption coefficients of four samples: computations (continuous line), characterizations (circles) and semi-empirical model (points) versus experiments (filled zone). 
As illustrated in Fig. 2 (see also Supplemental Material), computed results are in agreement with experimental data. We point out that there are no adjusted parameters in the proposed method. The results also reveal that those foam samples have distinct behaviors in terms of sound performance for given frequency bands. In particular, the sample $\mathrm{A}_{1}$ with $f_{c}=29 \%$, which can be considered as an open cell foam, has poor sound absorption capacity in the whole range of frequency and reached $\alpha \sim 0.5$ at $4500 \mathrm{~Hz}$. Interestingly, for $f_{c}=45 \%$, i.e. with a slightly higher membrane content, the absorbing ability is significantly improved. This effect is magnified as the closed fraction increases above 60\%: sample $\mathrm{A}_{3}\left(f_{c}=65 \%\right)$ and $\mathrm{A}_{4}$ ( $f_{c}=81 \%$ ) have interesting sound absorption properties, displaying increased performance in the low frequency band. The enhanced low frequency sound absorption corresponding to sample $\mathrm{A}_{4}$ correlates with an increase in tortuosity together with a decrease of the other transport parameters (Fig. 3). However, this enhanced low frequency sound absorption is accompanied with a decrease of the average sound absorption in the whole frequency range (Fig. 2).

Our predictions are also compared with measurements and models available in the literature. A simplified approach, referred to as a semi-empirical (2-parameter) model, has been proposed by Doutres et al. [5] in assuming a micro-/macro correlation based on the cell size $D_{b}$ and a reticulated rate $R_{W}=1-x_{f c}$. It can be seen from Fig. 2 that Doutres $e t$ al. model cannot be used to predict the sound absorbing behavior of foams in which a fraction $\left(x_{p}\right)$ of windows are partially closed. This justifies the development of an advanced modeling of the membrane content, such as the one proposed in this communication. The indirect method as proposed by Panneton and Only $[22,25]$ provides an experimental characterization of the macroscopic parameters $\left(\Lambda^{\prime}, \alpha_{\infty}, \Lambda\right.$ and $\left.k_{0}^{\prime}\right)$ from measured effective density and bulk modulus (assuming a 3microphone impedance tube, and available estimates of $\sigma$ and $\phi$ ) by using analytical solutions derived from the JCAL model. Fig. 3 illustrates the comparison between computed and characterized values of the non-dimensional macroscopic parameters as a function of $f_{c}$. The numerical results are presented as mean \pm standard deviation. Such values are obtained with a relative error on $r_{c}$ being equal to $5 \%$. The numerical estimates agree generally well with the experimentally measured values.
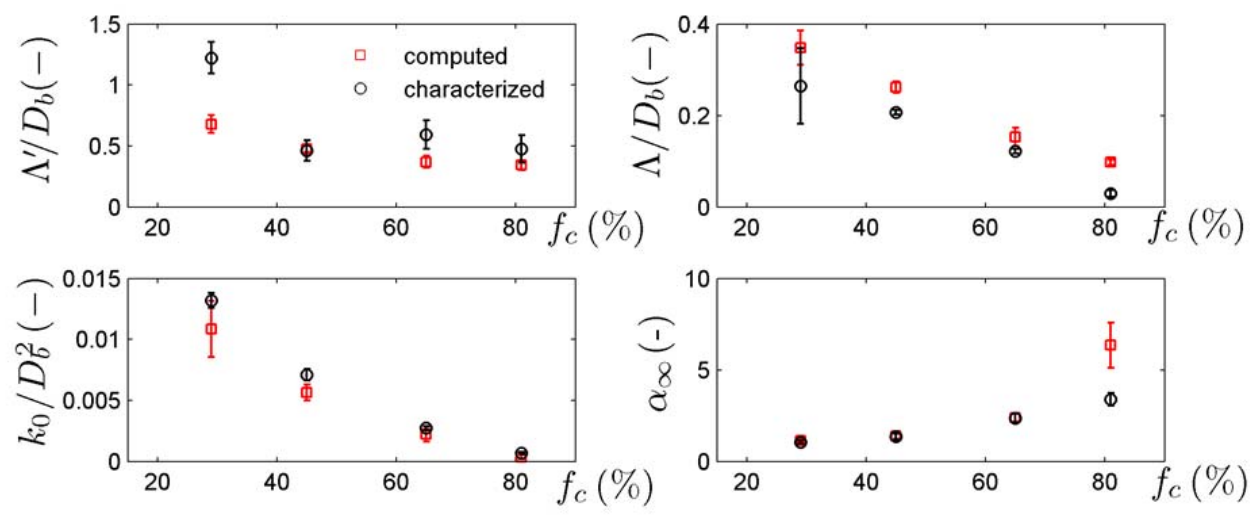

Figure 3: Dependence of dimensionless transport parameters on the membrane closed fraction $f_{c}$. 


\section{CONCLUSION}

Polymer foams with tuned values of the pore closure rate were elaborated. Their acoustical properties were studied experimentally. Three-dimensional periodic unit cells were then reconstructed, accounting for a detailed microstructural characterization. The membrane content was evaluated by measuring the proportion of fully and partially closed windows, together with the average closure degree of the partially closed ones. This treatment was refined by distinguishing the windows counting 4 or less edges from the windows counting more than 4 edges. Then, the corresponding 3D PUC serve as a basis to compute from numerical homogenization techniques transport parameters entering into the classical semiphenomenological models from which an approximate but robust description of the sound absorption can be determined on a microphysical background. Results showed good agreement between computed and experimental transport and sound absorbing properties and revealed how the membrane content can be finely tuned to control the absorption of long wavelength acoustic waves. The present coupled experimental/numerical approach shows an interesting way for enhancing the functionality of porous materials within the context of sound absorption. We demonstrated in this work that a systematic link between structure, property, and elaboration of foams can be achieved. It should therefore be possible to tailor the acoustical properties of these materials by controlling both the pore size and the membrane content. Further work will follow on the proposed approach for highlighting fully optimized materials.

\section{ACKNOWLEDGEMENTS}

Van Hai Trinh gratefully acknowledges the financial support from the Government of Viet Nam. This work was part of a project supported by ANRT (Grant no. ANR-13-RMNP-0003-01).

\section{REFERENCES}

[1] L. J. Gibson and M. F. Ashby, Cellular solids: structure and properties: Cambridge university press, 1999.

[2] C. Perrot, R. Panneton, and X. Olny, "Periodic unit cell reconstruction of porous media: Application to open-cell aluminum foams," Journal of Applied Physics, vol. 101, p. 113538, 2007.

[3] N. Kino and T. Ueno, "Evaluation of acoustical and non-acoustical properties of sound absorbing materials made of polyester fibres of various cross-sectional shapes," Applied Acoustics, vol. 69, pp. 575-582, 2008.

[4] O. Doutres, N. Atalla, and K. Dong, "Effect of the microstructure closed pore content on the acoustic behavior of polyurethane foams," Journal of Applied Physics, vol. 110, p. 064901, 2011.

[5] O. Doutres, N. Atalla, and K. Dong, "A semi-phenomenological model to predict the acoustic behavior of fully and partially reticulated polyurethane foams," Journal of Applied Physics, vol. 113, p. 054901, 2013.

[6] K. Yasunaga, R. Neff, X. Zhang, and C. Macosko, "Study of cell opening in flexible polyurethane foam," Journal of cellular plastics, vol. 32, pp. 427-448, 1996.

[7] X. Zhang, H. Davis, and C. Macosko, "A new cell opening mechanism in flexible polyurethane foam," Journal of cellular plastics, vol. 35, pp. 458-476, 1999. 
[8] C. Zhang, J. Li, Z. Hu, F. Zhu, and Y. Huang, "Correlation between the acoustic and porous cell morphology of polyurethane foam: Effect of interconnected porosity," Materials \& Design, vol. 41, pp. 319-325, 2012.

[9] M. T. Hoang and C. Perrot, "Solid films and transports in cellular foams," Journal of Applied Physics, vol. 112, p. 054911, 2012.

[10] M. T. Hoang, G. Bonnet, H. T. Luu, and C. Perrot, "Linear elastic properties derivation from microstructures representative of transport parameters," The Journal of the Acoustical Society of America, vol. 135, pp. 3172-3185, 2014.

[11] K. Gao, J. van Dommelen, and M. Geers, "Microstructure characterization and homogenization of acoustic polyurethane foams: Measurements and simulations," International Journal of Solids and Structures, 2016.

[12] D. L. Johnson, J. Koplik, and R. Dashen, "Theory of dynamic permeability and tortuosity in fluidsaturated porous media," Journal of fluid mechanics, vol. 176, pp. 379-402, 1987.

[13] Y. Champoux and J. F. Allard, "Dynamic tortuosity and bulk modulus in air-saturated porous media," Journal of applied physics, vol. 70, pp. 1975-1979, 1991.

[14] D. Lafarge, P. Lemarinier, J. F. Allard, and V. Tarnow, "Dynamic compressibility of air in porous structures at audible frequencies," The Journal of the Acoustical Society of America, vol. 102, pp. 1995-2006, 1997.

[15] B. Haffner, Y. Khidas, and O. Pitois, "The drainage of foamy granular suspensions," Journal of colloid and interface science, vol. 458, pp. 200-208, 2015.

[16] M. R. Stinson and G. A. Daigle, "Electronic system for the measurement of flow resistance," The Journal of the Acoustical Society of America, vol. 83, pp. 2422-2428, 1988.

[17] T. Iwase, Y. Izumi, and R. Kawabata, "A new measuring method for sound propagation constant by using sound tube without any air spaces back of a test material," in INTER-NOISE and NOISECON Congress and Conference Proceedings, 1998, pp. 1265-1268.

[18] Y. Salissou and R. Panneton, "Wideband characterization of the complex wave number and characteristic impedance of sound absorbers," The Journal of the Acoustical Society of America, vol. 128 , pp. 2868-2876, 2010.

[19] J. Rubinstein and S. Torquato, "Diffusion-controlled reactions: Mathematical formulation, variational principles, and rigorous bounds," The Journal of chemical physics, vol. 88, pp. 63726380, 1988.

[20] C. Perrot, F. Chevillotte, M. T. Hoang, G. Bonnet, F.-X. Bécot, L. Gautron, et al., "Microstructure, transport, and acoustic properties of open-cell foam samples: Experiments and three-dimensional numerical simulations," Journal of Applied Physics, vol. 111, p. 014911, 2012.

[21] I. Cantat, S. Cohen-Addad, F. Elias, F. Graner, R. Höhler, O. Pitois, et al., Foams: structure and dynamics: Oxford University Press, 2013.

[22] R. Panneton and X. Olny, "Acoustical determination of the parameters governing viscous dissipation in porous media," The Journal of the Acoustical Society of America, vol. 119, pp. 2027-2040, 2006.

[23] E. B. Matzke, "The three-dimensional shape of bubbles in foam-an analysis of the role of surface forces in three-dimensional cell shape determination," American Journal of Botany, pp. 58-80, 1946.

[24] L. Gong, S. Kyriakides, and W.-Y. Jang, "Compressive response of open-cell foams. Part I: Morphology and elastic properties," International Journal of Solids and Structures, vol. 42, pp. 1355-1379, 2005.

[25] X. Olny and R. Panneton, "Acoustical determination of the parameters governing thermal dissipation in porous media," The Journal of the Acoustical Society of America, vol. 123, pp. 814824, 2008. 